\title{
Supporting self-regulated learning and personalization using ePortfolios: a semantic approach based on learning paths
}

\author{
Lucila Romero $^{1 *}$ D, Camila Saucedo ${ }^{1}$, Ma. Laura Caliusco ${ }^{2}$ and Milagros Gutiérrez ${ }^{2}$
}

\footnotetext{
* Correspondence: lucila.rb@gmail. com

${ }^{1}$ Facultad de Ingeniería y Ciencias Hídricas, GIDIS Research Group, Universidad Nacional del Litoral, Ciudad Universitaria, 80 Ruta Nacional 168, Santa Fe, Argentina Full list of author information is available at the end of the article
}

\begin{abstract}
In the area of e-learning, there are new challenges to be overcome. One of them is to allow students self-regulation of their learning. Within this self-regulation process, students and teachers use technological tools to carry out their tasks. In general, these tools do not consider pedagogical aspects. Emerging approaches propose the use of electronic portfolios and semantic technologies to provide pedagogical characteristics that make tools more user-friendly for both teachers and students. This paper presents a conceptual model of an intelligent system to support self-regulated learning. This model is based on semantic technologies and uses the concepts of learning paths and student e-portfolios. For learning path generation, the system considers the different learning levels that a student should achieve and metrics that measure student progress. In this way, it proposes a learning path with the intention that the student achieves as highest learning level as possible.
\end{abstract}

Keywords: Learning path, E-learning, Ontology, Self-regulation, Personalization, E-portfolio, Educational resource

\section{Introduction}

E-learning has allowed courses spread through the world overcoming time and space boundaries established in classrooms. This produced many benefits: enhanced student participation, better communication between students and teachers, and motivation to work in a collaborative way, among others. However, all technologies change over time and this context is not an exception. It is necessary not only innovate, but also solve problems and challenges that arise day to day.

The application of information and communication technologies (ICT) in education does not mean that presence of a teacher who plans, organizes, guides and assesses learning should be left aside. ICT must assist teachers in developing better pedagogical and didactical methods taking into account differences between students. Some studies such as those introduced by Marques, Villate, and Carvalho (2017); Meira Ferrão Luis, Llamas-Nistal, and Fernández Iglesias (2017); Morais, Alves, and Miranda (2017) highlight the importance of analysing data generated by Learning Management Systems

(C) The Author(s). 2019 Open Access This article is distributed under the terms of the Creative Commons Attribution 4.0 International License (http://creativecommons.org/licenses/by/4.0/), which permits unrestricted use, distribution, and reproduction in any medium, provided you give appropriate credit to the original author(s) and the source, provide a link to the Creative Commons license, and indicate if changes were made. 
(LMS). These systems gather a lot of information about student's action and activities, but teachers have difficulties to analyse and use it in order to improve their strategies.

Another aspect to take into account is the assessment of learning. Some researches evidence the importance of this process since it influences on the learning quality. So, student learning depends on how they are assessed and with which instruments (García Carreño, 2012). Moreover, assessment is a better way to keep students interested because they feel observed, guided and controlled. So, teacher assesses student to identify the evolution through different learning levels. On the one hand, according to the level achieved, instructor proposes actions and materials to improve student performance (Leyva Leyva, Proenza Garrido, Leyva Leyva, Varona, \& Romero Rodríguez, 2008) such as assessments, videos, essays, lectures, among others. On the other hand, each student learns at his/her own pace. This creates a need to personalize the mechanisms used according each student. Technologies can help teacher to discover who is learning and who is unmotivated. They may propose actions like when, whom and how assess or what activities can be done.

In this pedagogic-technological context, self-regulation of learning becomes a key factor. It is necessary that students use the technologies to plan, organize and facilitate their own learning. One of the available technologies to support this process is the e-Portfolio. An e-Portfolio is a digital folder where students collect and include material that evidences their learning progress. This helps them to identify which aspects dominate and which ones should improve (Barberà, Bautista, Espasa, \& Guasch, 2006). In addition, it allows teacher to better understand the individual characteristics of each student and attend different learning paces that can coexist in their group (Rico Martín, 2010). The e-portfolio must be prepared to support different digital materials, activities and learning methodologies adopted by teachers that can change over time. Using semantic technologies in its development is a step forward in order to support personalization and self-regulated learning.

According with related works, different aspects must be taken into account: (i) the use of learning path and learning levels in e-learning, (ii) the use of e-portfolios in the learning process and how it facilitates self-regulation learning and (iii) the use of semantic technologies to develop this tool.

With respect to the first one, Peres, Oliveira, Jesus, and Silva (2017) present an implementation of learning path into e-learning platform, taking into account the seven learning level defined by Bloom (Bloom, Engelhart, Furst, Hill, \& Krathwohl, 1956). However, it does not allow students to take a different path according with their capabilities and learning pace.

As regards the use of e-portfolios in the learning process, Encalada, Santiesteban, Portela, Cruz, and Arboleda (2017) implement an e-portfolio in the Mahara platform adapted to the Lesson Study model, which facilitates the collaborative work of the learners in Educational Sciences careers in their pre-professional practices. Weber and Myrick (2018) analyse the experiences of undergraduate students in a summer research program and the development of e-portfolios through free web pages such as Wix and WordPress. Chittum (2018) suggests, in an introductory course of educational psychology for teachers, the use of deepen learning and motivation thought the implementation of e-Portfolios based on the Digication web platform. Collins and O'Brien (2018) use e-portfolio implemented in the Pathbrite platform for the nursing 
bachelor program of the School of Nursing, at Otago Polytechnic. Many of these underline aspects correspond to what Alexiou and Paraskeva (2010) mention: the use of e-portfolios implies carrying out processes of reflection, planning, synthesis, presentation, discussion and feedback, which are part of self-regulated learning.

In addition, the above-mentioned works have other aspect in common. They do not use semantic technologies in the implementation of the e-portfolio. They use web pages or platforms available on the Internet contributing to the lack of personalization and interoperability. There are specifications such as IMS ePortfolio and JISC Leap2A that can be used for developing new e-portfolio systems solving interoperability problems. Nevertheless, they are based on the XML language, in which the semantic of the elements is comprehensible by humans but not by machines (Rezgui, Mhiri, \& Ghédira, 2018).

Finally, in respect of use of semantic web technologies in e-portfolio implementation, Taibi, Gentile, Fulantelli, and Allegra (2010) develop an ontology that reuses and extends the concepts of the FOAF (Friend Of A Friend) ontology to include e-portfolio concepts, but it is oriented only to informal learning activities. Wang and Wang (2012) describe an ontological approach to organize the resources in an e-portfolio, but it is not implemented in a formal language like OWL. Nguyen and Ikeda (2014) propose an ontological model that is used to design and implement an ePortfolio system in order to promote self-regulated learning. Rezgui et al. (2018) develop an ontology to represent different types of e-portfolios and their resources, based on standards and official specifications like IMS ePortfolio and JISC Leap2A. Although these models present a great advance in the use of semantic tools, they do not use the concept of learning paths, a feature that further enriches personalization.

In previous work, authors propose an ontology network called AONet where the portfolio concept has been developed as the container of student assessment and tracking (Romero, Gutiérrez, \& Caliusco, 2017, 2018).

The present work extends this network, adding a conceptual model of an intelligent system that uses the concept of learning paths based on portfolios to self-regulate learning. It is based on semantic technologies to provide an automatic generation of learning path taking into account the individual learning paces, capabilities and motivations of students. In this way, the portfolio concept is useful as the tool to collect students' experiences and their interaction with teacher. Also, the learning level concept allows system to infer recommendation for each student.

The proposed intelligent system will be a useful tool for teachers and students. On the one hand, it will provide recommendations to guide learning activities and select educational resources according the possibilities of each student. This will allow teachers to personalize learning. On the other hand, students will be able to estimate and recognize their learning progress to make decisions that will affect and improve their performance within the possibilities offered by the course.

This work is organized as follow. Background section presents background about previous works, portfolio, learning path and learning levels. Intelligence system conceptual model based on semantic technologies section presents the intelligent system conceptual model. It describes Educational Resources ontology and Learning Path ontology proposed. Also, it shows the use of the model through the derivation rules implemented in the ontology and agent rule. Finally, this work is concluded. 


\section{Background}

\section{AONet ontology network}

An ontology can be defined as "a formal, explicit specification of a shared conceptualization” (Studer, Benjamins, \& Fensel, 1998). This means, ontologies are abstract models of specific domains represented by concepts, relationships between concepts and restrictions, defined and agreed by a group of people. In addition, they are understood not only by humans, but also by machines.

An ontology network is a group of ontologies related together through a variety of different relationships such as mapping, modularization, version and dependency. The elements of this group are called networked ontologies (Allocca, d'Aquin, \& Motta, 2009). AONet has four domains: course topic, agent, educational resources and assessment. Figure 1 shows AONet's ontologies and meta-relationships. An Assessment is an Educational Resource and has Metadata that describe it. A Portfolio is an Educational Resource too. In order to develop an Assessment, different Instruments can be used. An assessment evaluates topics or subjects that must be learned, which are conceptualizing in Course domain ontology. Agent domain represents the stakeholders involved in an educational process. This work focuses on Educational Resources, Learning Path and Portfolio ontologies, in order to provide terms and relationships to model and enable personalization and self-regulated learning. In previous works, the authors have described the other ontologies of the AONet network.

\section{Portfolios}

Portfolio is one of the tools available to evaluate learning. It has been originally used for staff training in workplaces, but today, it is evident the role it plays in educational contexts. Particularly, the use of portfolios in higher education has different purposes, such as: (i) introducing student or educator, (ii) planning personal development and (iii) continuous learning. Students collect and select materials from their university careers and create a body of work that represents their achievements throughout the training process.

Portfolios are useful tools to include in the learning process. When they are used mediated by ICT, they are called e-Portfolios. An e-Porfolio is a digitalized collection of

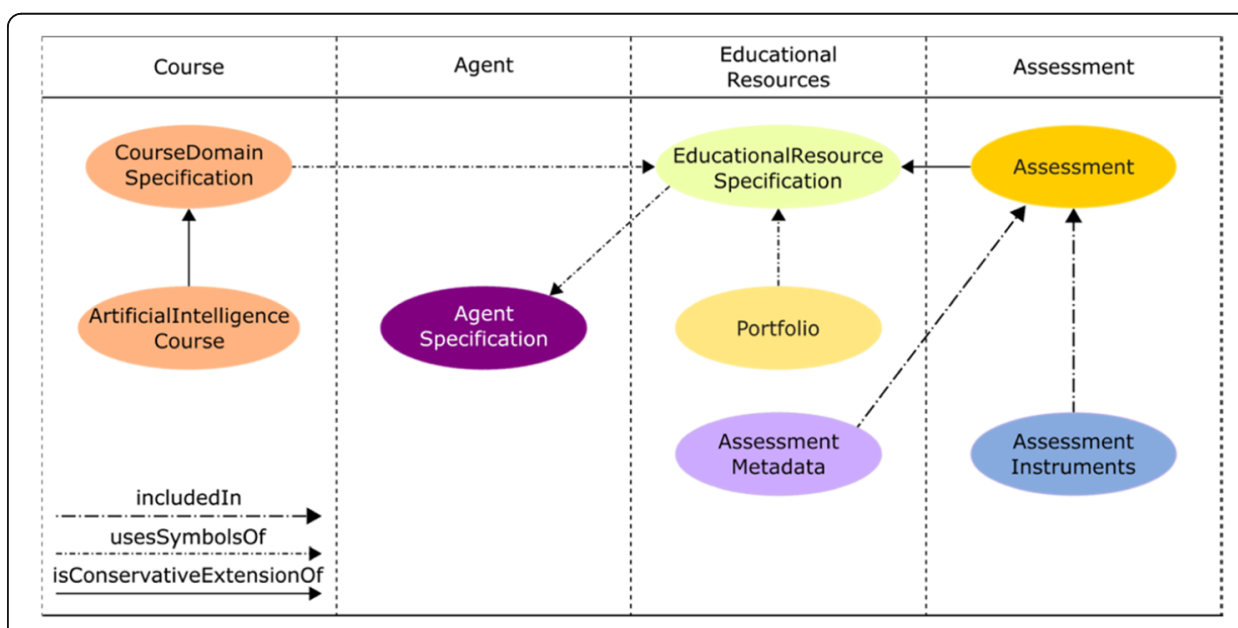

Fig. 1 AONet ontology network 
artefacts that includes learning demonstrations, comments, educational resources, teacher feedback and assessment results that represent an individual, group or institution (Barrett \& Garrett, 2009; Lorenzo \& Ittelson, 2005). If its main purpose is the assessment of learning outcomes, it is referenced as e-portfolio assessment (Chang, Tseng, \& Lou, 2012).

The e-portfolio, as an assessment tool, provides the possibility to evaluate the way in which each student learns (Mason, Pegler, \& Weller, 2004). Teachers can include in it different assessments that allow them to measure progress in learning. These elements can be objective tests, essays and conceptual maps, among others. So, the e-Portfolio provides students authentic and reflective evidence, with interactive and individual characteristics. This constitutes an advance in ICT-based exams (Bolivar, 2011).

Each learner should have their own e-Portfolio and should feel committed to organize it in the best way, under the guidance of her/his teacher. In this way, this tool stimulates the student's active work and helps to develop reflective thinking, contributing to self-regulation of learning. Thus, it is important to establish the criteria for building and completing portfolio. Considering specifically the evaluation process, teacher can propose a set of different types of exams that the student must solve, such as: self-assessment, hetero-assessment or peer-assessment (Chang et al., 2012). All the evaluations solved by learners will be contained in their portfolios available to the teacher. This has a double purpose: on the one hand, teacher estimates the learning level achieved by the student and, on the other hand, student is able to regulate her/his own learning. In this type of learning, students become proactive in their efforts to learn, know their strengths and limitations, establish personal goals and define strategies to achieve them, monitoring their progress and improving the methods they use to learn (Zimmerman, 2002).

The use of e-Porfolios has increased in the field of educational institutions as a valuable tool for continuous learning, not only for distance education but also for face-to-face careers. In recent years, a large number of e-Portfolio systems have been developed, as can be seen in EPAC: ePortfolio-related Tools and Technologies (2018). These tools must be integrated into learning management systems (LMS), offering different functionalities.

All those characteristics make e-portfolio a flexible tool that can support different purposes, contexts, resources and approaches or theories of teaching and learning. In addition, it can be implemented at different institutions and platforms. Semantic Web technologies, like ontologies are appropriated tools to achieve the goals of personalization and interoperability and that is why innovation through this way is necessary.

Figure 2 shows the e-Portfolio ontology proposed in this work.

\section{Learning path}

Students need to do some activities or actions in order to achieve learning goals. The set of learning actions that guide the students are known as learning paths. There are different types of learning actions such as formal, semi-formal, and informal or a combination of these. In addition, they can have various complexity levels, from very simple activities; like watch a video, to very complex ones, such as following a complete curriculum (Janssen, Berlanga, Vogten, \& Koper, 2008). 


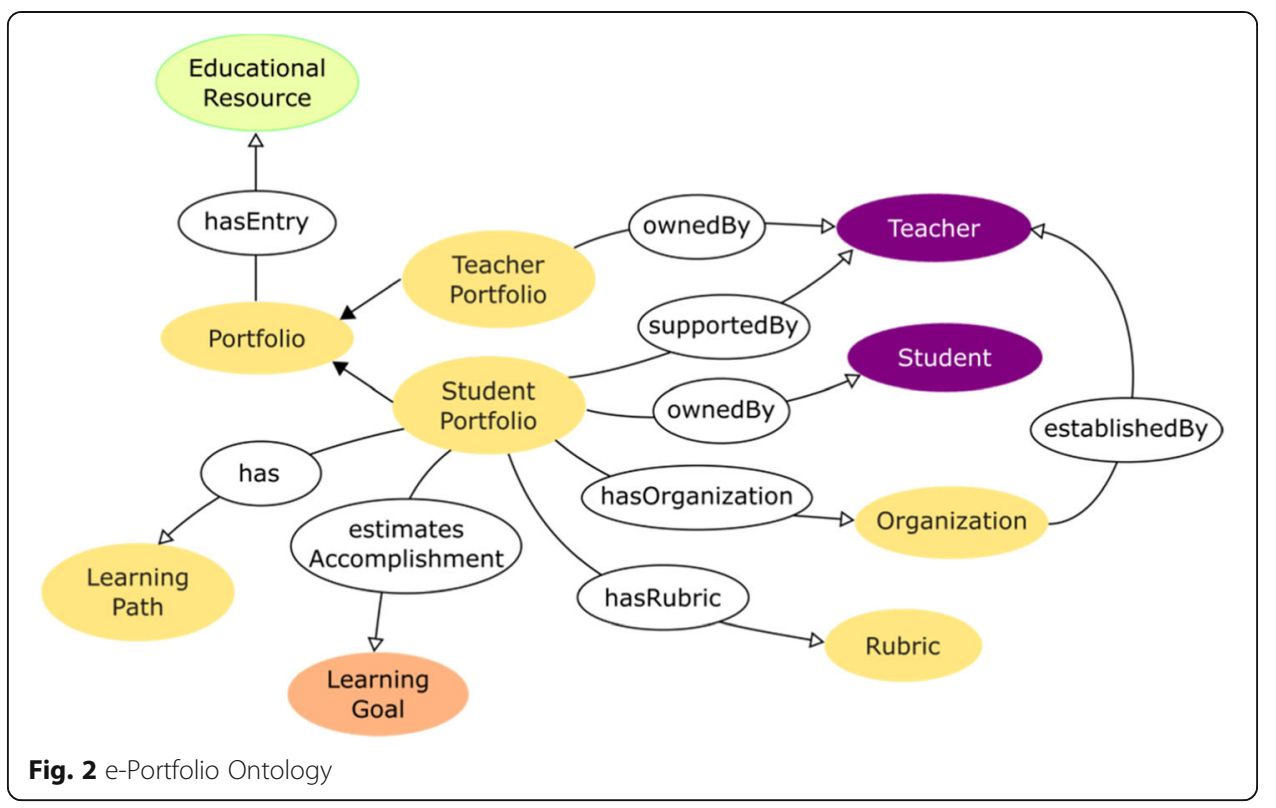

Online courses use the learning path concept, in order to guide students through sequentially related content. It helps students become proficient in a specific technology in a short time.

\section{Learning level}

When teachers plan a course, they identify the curricula and objectives according with knowledge, skills and attitude that a student must achieved. Therefore, the learning content and the level of assimilation pursued must be consistent with course objectives. To achieve them, educator plans his classes selecting the most appropriate methodology (Jaramillo Roldán, 2004).

Teacher give students the appropriated learning objects (LO), with which students interact during a course. A LO is the scientific information that has concepts, activities and assessment used in a course. Each LO has a learning level associated that represents its difficulty level with a value. Therefore, in the way that students reach the satisfactory level of each LO, they meet a ranking into the assimilation knowledge level. In this paper authors consider the following levels that students can achieve (Jaramillo Roldán, 2004; Leyva Leyva et al., 2008): (i) first learning level: know, make sense, understand something. At this level, students learn by heart, it is to say, they keep concepts in mind and can reproduce the information. However, they cannot reason or exercise knowledge appropriately. (ii) Second learning level: cognitive learning, deep learning. This level involves mental processes in learning. Learners gain knowledge, skills and experiences to apply in both real life and to solve problems. Students at this level can observe, categorize and form generalization to make sense of the information provided. The learning results come from mental activities but not from externals stimulus. (iii) Third learning level: Create, evaluate and modify the knowledge to take into account new information. Students at this level can justify a decision or course of action, generate new ideas, design new things, construct, plan and make hypothesis, among others. 
Each of these levels requires different learning activities: from simple ones such as lectures, commented readings or films, to more complex ones like debates, trials or case studies. The more complex is the activity, the higher level it will be reached.

In this way, educator must know the knowledge level students can reach with the learning material provided. For example, if teacher usually use expository classes as a learning method, student will only be handling the content in the first level of assimilation, that is, learning by heart (Nalda, 2002).

There are different indicators that give teacher the certainty that the highest level of assimilation was achieved. For instance, when student discovers new relationships and applies concepts learned to solve real problems with certainty and success.

Scores are usually used to obtain an overview of success or failure of learning and are useful to assess students. These are not homogeneous indicators as a measure of the learning process results. This is because they depend on the teacher's criteria when he/ she designs learning process or evaluates learners. In this sense, scores are a very weak indicator of the quality of learning process, so it should always be complemented with other types of indicators and criteria (Escudero Escorza, 2000).

Teachers frequently fail when evaluate the learning level achieved by students. They usually develop and apply rigid evaluations that require textual reproduction of concepts, which is irrelevant for professional life. They should use different learning objects that belong to different levels of assimilation. Then, they should consider different indicators and criteria to determine what level the student reached and what actions are necessary to continue learning.

\section{Intelligence system conceptual model based on semantic technologies Methodology}

AONet ontology network has been developed with the NeOn methodology ( $\mathrm{NeOn}$ Project, n.d.). This is an open service-centred reference architecture for managing the complete life cycle of networked ontologies. It is a scenario-based methodology that supports collaborative work and reuse (Suárez-Figueroa, 2010).

From a model integration point of view, within an ontology network each ontology conceptualizes a specific domain and plays a particular role. Then, the main advantage of using an ontology networks is the conceptualization of a given domain in a modular way (Welty \& Guarino, 2001). Also, each ontology within the network is simple enough and easy to maintain and understand than a complex one. In addition, several designers could work on different networked ontologies concurrently.

In order to identify ontologies requirements and user scenarios, they were defined different competency questions proposed by Grüninger and Fox (1995).

\section{Educational resource ontology}

EducationalResource ontology conceptualizes the resources used by teachers in courses.

Figure 3 shows the main concepts and relationships defined in this ontology.

The main element is the EducationalResource term, which represents all the learning objects that a teacher uses in her/his class for teaching a given content. The isRequiredBy relationship relates EducationalResources and Content terms. This relation means that for teaching a planned content it is required some educational resources 


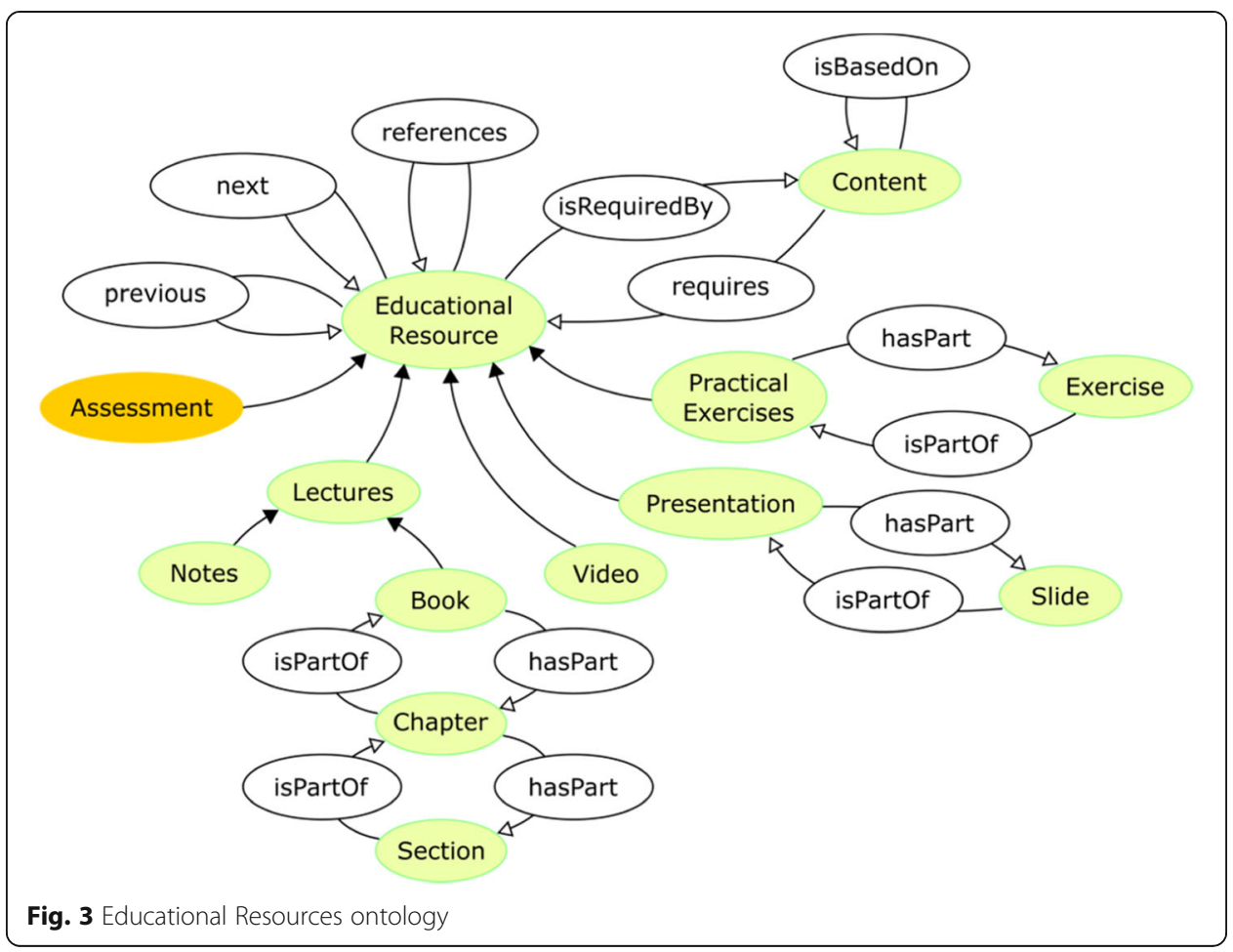

(Stojanovic, Staab, \& Studer, 2001). In addition, Content has an isBaseOn self-relationship, which means that a content uses definitions and concepts from other contents. This establishes an order among them.

The EducationalResources term could be specialized in multiple concepts representing each one the wide variety of resources currently used in e-learning. This work shows the most used resources in the Information Systems Engineering and Computer Engineering knowledge areas.

The Lectures term models theories, concepts and lessons, among others. The Notes term is a subtype of Lectures, which expresses the notes developed by teachers to introduce and develop concepts. Another subtype of Lectures is Book, which models the study books. Teachers can give complete books, book chapters or specific sections. In the ontology, the hasPart relationship represents the composition among Book, Chapter and Section terms. The isPartOf relationship is the inverse of hasPart relationship (Stojanovic et al., 2001).

The PracticalExercises term expresses the practical works proposed by teachers, containing exercises. Students can solve them putting into practice the learned concepts. Then, the isPartOf relationship relates Exercise and PracticalExercises terms. This means that a practical work is composed of exercises. In others words, a practical exercises is an educational resource composed of exercises that is required for teaching a content.

The Presentation term models the presentations that teachers use in their classes to teach a topic or content. The hasPart composition relationship relates it with Slide term.

Assessment is a subclass of EducationalResources. It represents the evaluations or tests and it has been developed previously in (Romero, Gutiérrez, \& Caliusco, 2016).

EducationalResources has the previous and next relationships that indicate the sequence in which the resources must be accessed. Figure 4 shows an example with 


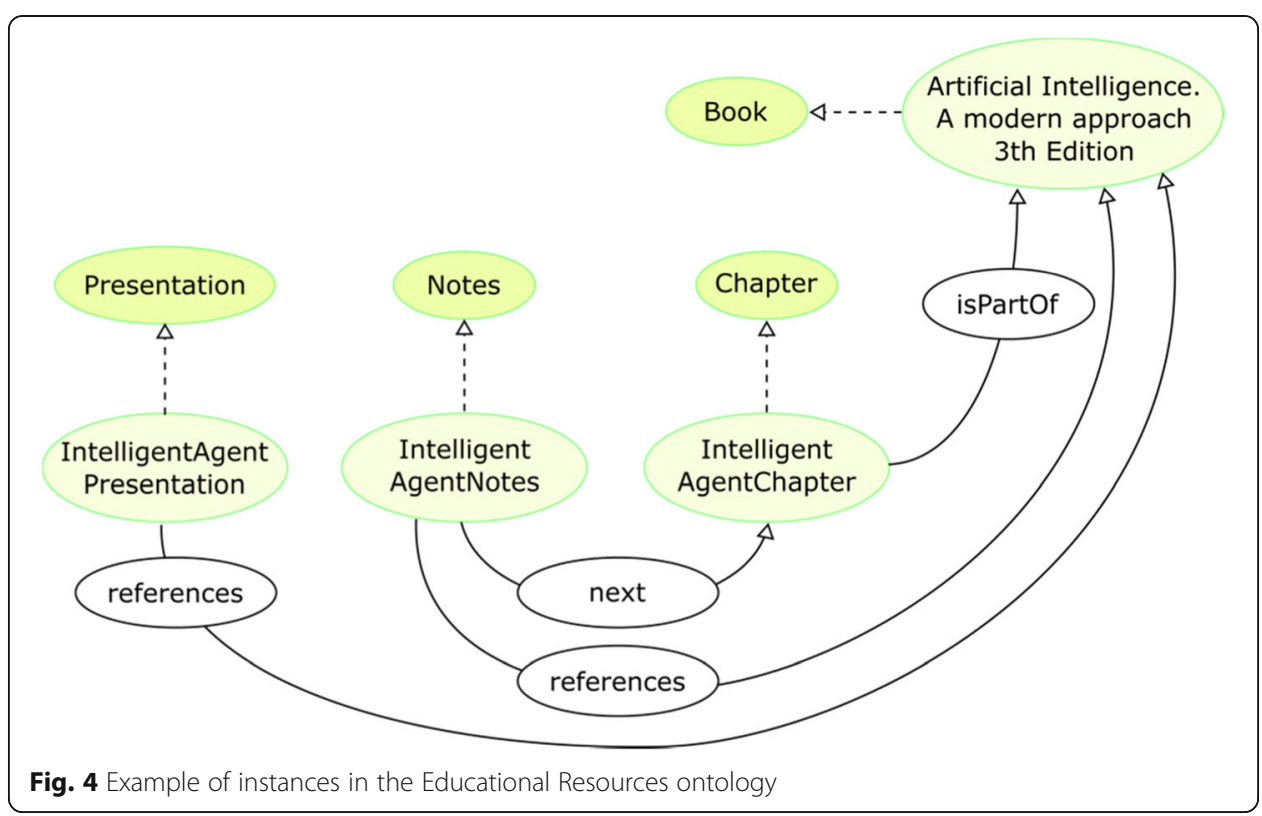

ontology instances. Thus, in order to teach the topic Intelligent agent there are three instances: an IntelligentAgentChapter book chapter, an IntelligentAgentNotes note and an IntelligentAgentPresentation presentation, where the intelligent agent note instance has a next relationship with the intelligent agent book chapter instance. In this way, the note must be accessed before than the book chapter.

Another self-relation in EducationalResources is reference relationship, which means that an educational resource can have references to others. Figure 4 also shows an example of this. The IntelligentAgent Presentation and the IntelligentAgentNotes have a bibliographical reference to Artificial Intelligence A modern approach, 3th edition book. Therefore, students can read this book to understand the concepts better than in the note or in the presentation.

\section{Learning path ontology}

As already said, it is important that students feel observed and evaluated continuously in order to keep in contact with their teacher and thus continue learning. The learning path ontology has been developed based on student's portfolio ontology (StudentPortfolio) that organizes the materials and student's interaction. Thus, a StudentPortfolio concept has an associated LearningPath concept. Figure 5 shows the relation between StudentPortfolio and LearningPath in the AONet Ontology network.

Figure 6 shows the Learning path ontology. As we can see, LearningPath concept is composed of nodes (Node) sorted through the next relationship. A Node can adopt different meanings according with teacher criteria and course syllabi. Thus, a Node could represent for instance a subject, an assignment and a unit, among others. Each Node is composed of one or more Content, which is associated with EducationalResources. In addition, a Node has a mandatory level associated, which is conceptualized through MandatoryLevel concept. It has two instances: core and optional. Then, if a Content has the core instance associated, it represents a mandatory content and student must 


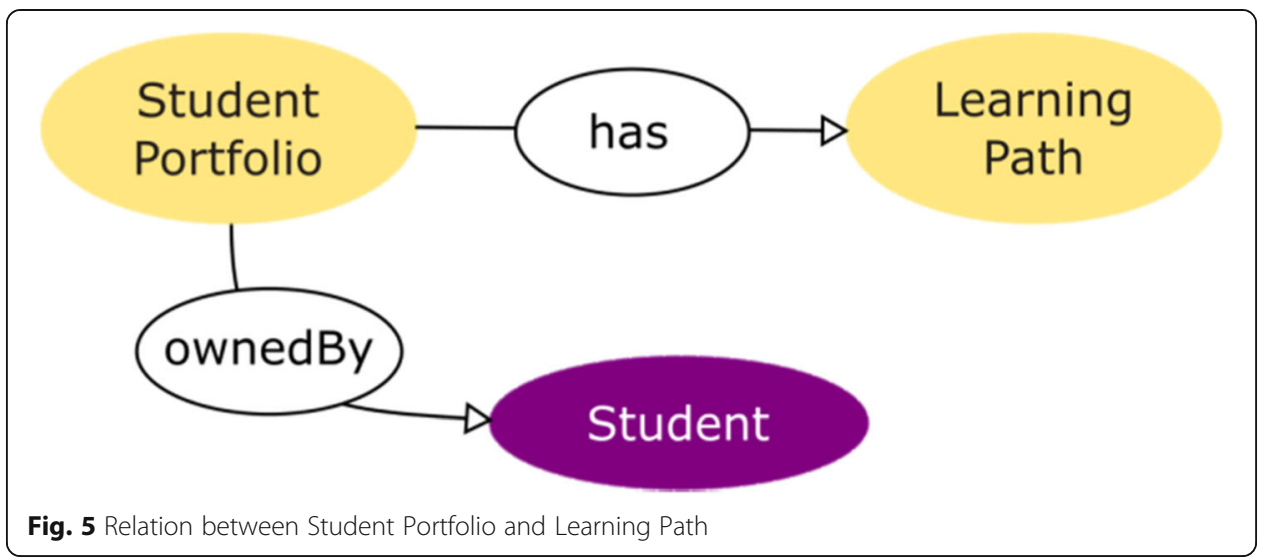

solve it. In other case, student can choose if solve it or not. Educator can propose optional content both, when student not meet the objectives and need another lessons, and when student overcome them and there are new upper levels to achieve.

Both Content and Node have state and condition associated. The state can be available or unavailable, and the condition can be solved and unsolved. As regards state, when a node has the available instance associated, then each content in the node becomes available too. In the ontology, the ContentState and the NodeState concepts represent the state of a content and a node respectively. As regards condition, the ContentCondition and NodeCondition concepts have two instances: solved and unsolved. If student has solved the content, then the instance solved is associated to it; in other case, it will be associated to the instance unsolved. If each content belonging to a node have associated the solved instance, then the node become solved too. As student solves

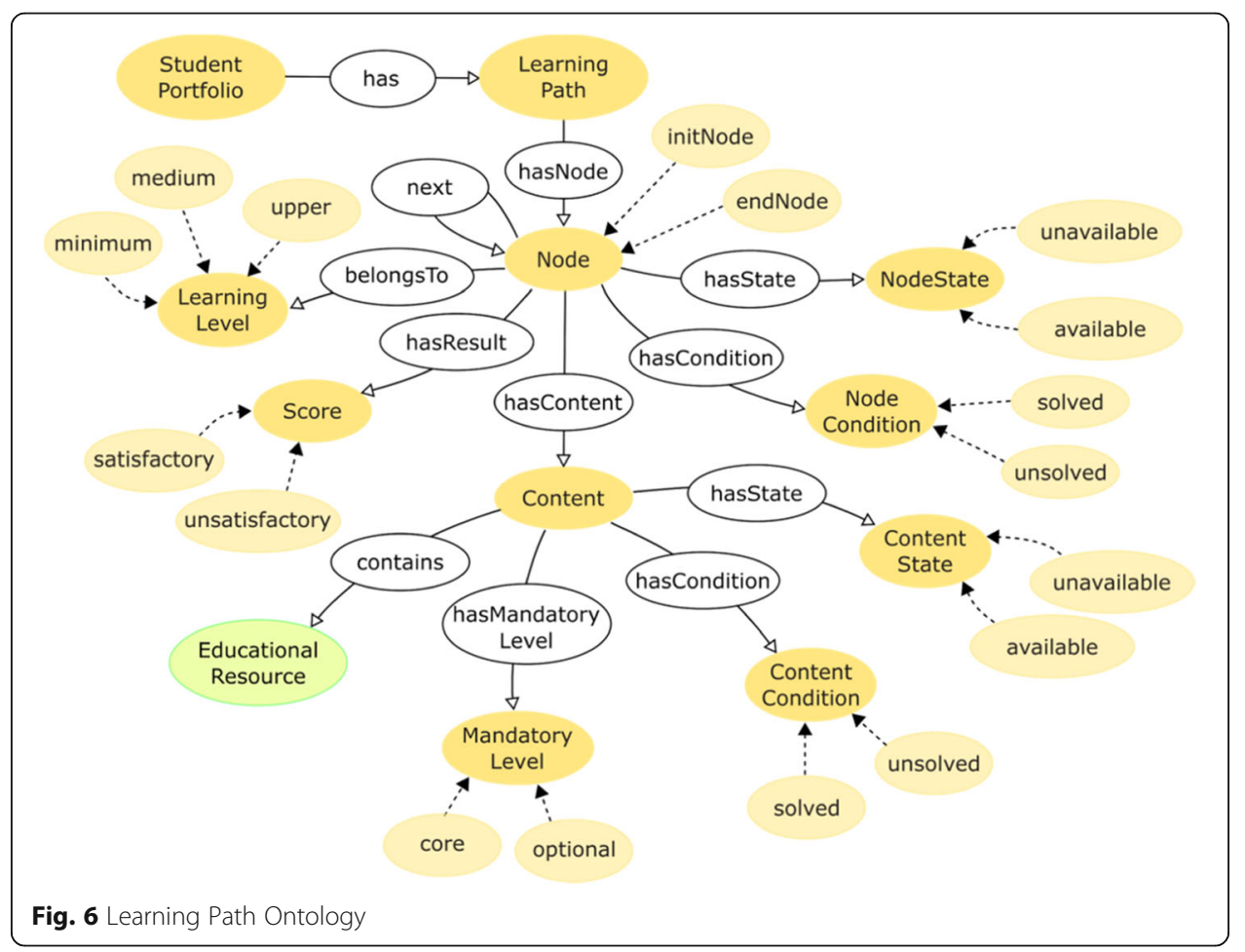


the contents, each one receives a Score and based on that, the node calculates its score. In the ontology, the Score concept has two instances: satisfactory and unsatisfactory. Educator can change these instances according with her/his criterion. Only when student meet the satisfactory score for a node, he/she can continue with the next node. Finally, each node of the learning path is associated to a LearningLevel, which can be minimum, medium or upper.

Based on this ontology, it is possible to implement logical rules that guide instructors when develop a course. For instance, a teacher might want his/her students go through two minimum levels before continuing at a medium level for a concept. In this sense, a node belonging to minimum level can only be followed by another node of the same level or the medium level, but not for a node belonging to higher level. In addition, the level of a node must be in correlation with the educational resources difficulty. It is to say; if teacher defines a node belonging to minimum level then the content must be associated with EducationalResources with low difficulty. Table 1 shows two examples of these rules.

Figure 7 shows an instantiation of learning path ontology, where it is showed a node and its contents. There is a unit1-agent node associated with the first unit in Artificial intelligence course, belonging to minimum level. This node has three learning material associated: an assessment, a note and a chapter. In the example, the node has not been solved yet by student and it is available. The restriction rule shown in Fig. 7, called WFN (Well Formed Node), indicates that the node is well formed if there is at least an assessment contained in it.

Figure 8 shows another example of learning path with five nodes belonging to different levels. Unit1-agent node is followed by two nodes. One is unit1-agent revision node, which is optional. In this case, if the student needs to revise this concept, he/she can access to this node to solve it. The other node is Unit1-agent type that belongs to minimum level. Then, the other two nodes Unit 1 - agent practice and Unit 1-agent app belong to medium and upper level respectively. The medium level node contains a practical work, where student needs to apply the concept in a laboratory environment. The upper level node contains an essay where student needs to solve a problem from a real case using a robot.

Table 2 shows recommendation rules that guide student through the learning path to follow. In this case, if student solves a node satisfactory, then the system recommends going forward to the next node. In addition, it is shown the Upper and High sets. The Upper set groups nodes that belong to upper level, while High set groups the learning material with high or very high difficulty level.

Table 1 Inference rules

\begin{tabular}{|c|c|}
\hline Description & Rule \\
\hline $\begin{array}{l}\text { A node of minimum level is followed by another node of } \\
\text { minimum level or medium level. }\end{array}$ & $\begin{array}{l}\text { Node(?n1)^Node(?n2)^ next(?n1,? n2)^ } \\
\text { belongsTo(?n1, "minimum") } \\
\rightarrow(\text { belongsTo(?n2, "minimum") ^ } \\
\text { belongsTo(?n2, "medium")) }\end{array}$ \\
\hline $\begin{array}{l}\text { The educational resources that are part of a node of minimum } \\
\text { level must have low difficulty }{ }^{a} \text { associated. }\end{array}$ & $\begin{array}{l}\text { Node(?n1)^ ^ontent(?c) ^hasContent(?n1,?c) } \\
\text { "belongsTo(?n1, "minimum") } \\
\rightarrow((\text { describedBy(?c, "easy") ^ } \\
\text { "very easy")) }\end{array}$ \\
\hline
\end{tabular}

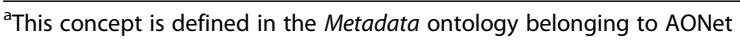




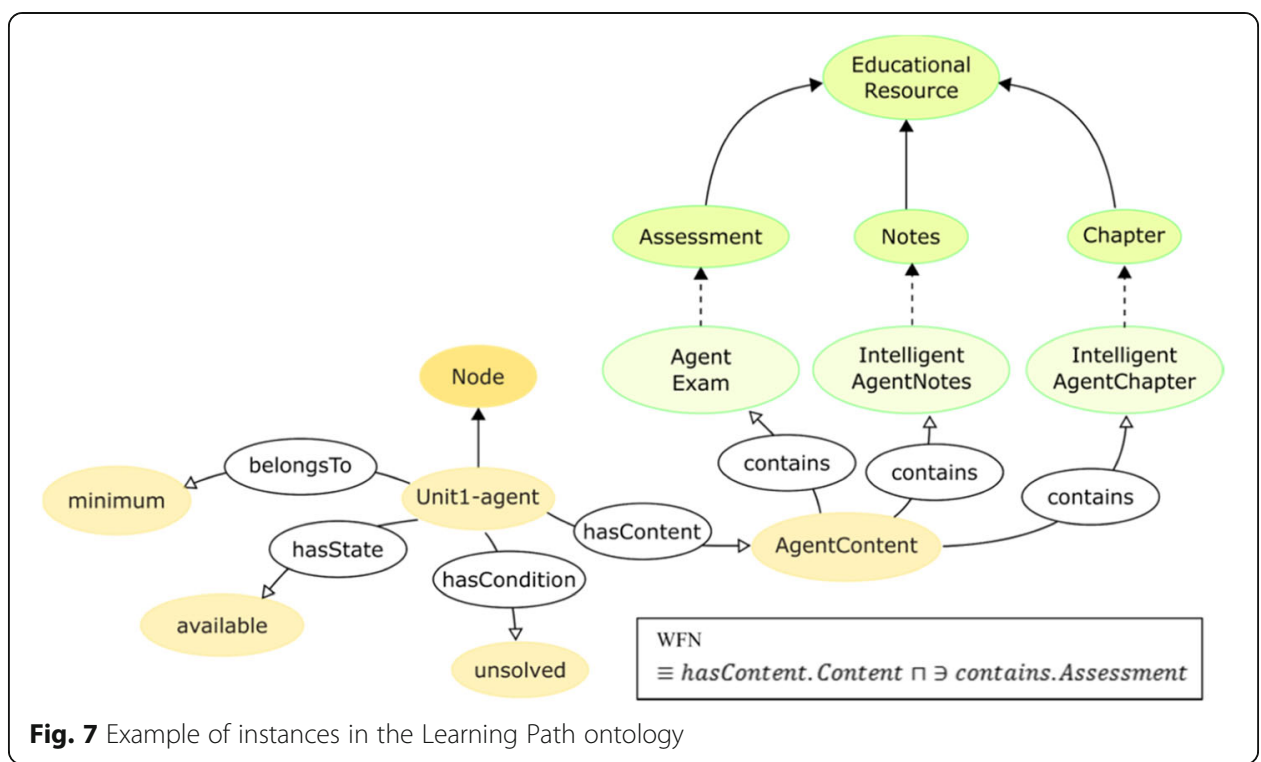

Fig. 7 Example of instances in the Learning Path ontology

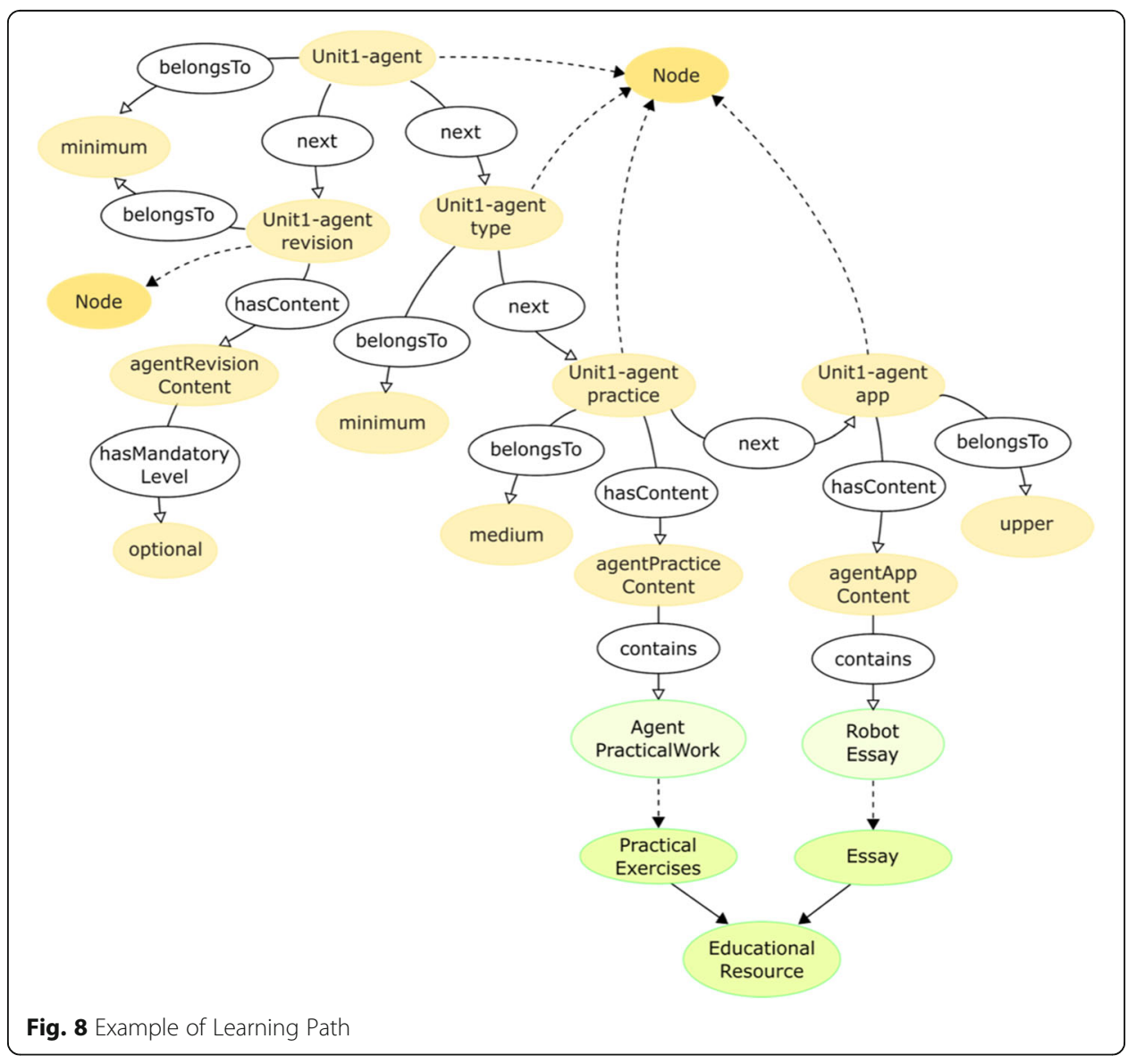


Table 2 Derivation rules and set definition

\begin{tabular}{|c|c|}
\hline Description & Rule \\
\hline If node result is satisfactory then recommend go forward & $\begin{array}{l}\text { Node(?p) ^hasResult(?p,? s) } \\
\text { `optimalLearningLevel(?॥) } \\
\text { ^sqwrl:greaterThanOrEqual(?s,?ll) } \\
\rightarrow \text { AnswerGoForward(?p) }\end{array}$ \\
\hline HIGH is the set of all learning materials which difficulty is high or very high. & $\begin{array}{l}\text { HIGH } \equiv \text { LearningMaterial } \Pi \\
\exists \text { describedBy.(difficulty("high") } \sqcup \\
\text { difficulty("veryhigh")) }\end{array}$ \\
\hline UPPER is the set of all nodes that belong to upper learning level. & $\begin{array}{l}\text { UPPER } \equiv \text { Node } \sqcap \\
\text { belongsTo.learningLevel("upper") }\end{array}$ \\
\hline
\end{tabular}

Table 3 shows agent rules in order to recommend actions. First rule says that if the derivation rule give the answer go forward, then the agent recommends go to the next node. Second rule recommends teacher to add an upper node if there is none. Third rule recommends an optional node in case that the score is minimum.

\section{Conclusions}

In this work, a conceptual model based on semantic technologies of an intelligent system to support self-regulated learning was presented. This model is beneficial for both students and teachers.

On the one hand, the model allows self-regulated learning, enabling students to be proactive in their efforts to learn, know their strengths and limitations, establish personal goals and define strategies to achieve them, monitoring their own progress and improving the methods, they use to learn.

On the other hand, the model allows the personalization of learning to help teachers in the complex task of directing learning process. This personalization consists of the selection of the appropriate educational resources according to the students' abilities and the objective of the course.

In order to facilitate self-regulation and personalization of learning, the conceptual model introduces the concept of learning path. Each step in the learning path relates the student's learning level and enables appropriate educational resources to go forward on learning. Here learning level is a data derived from indicators based on the information available in the student's e-Portfolio. In addition, the conceptual model is based on semantic technologies to provide an automatic generation of learning paths. This model comprises the different learning levels that a student can achieve and metrics that measure progress with the objective that each learner can reach the highest possible learning level.

Table 3 Agent rules

\begin{tabular}{l}
\hline Agent rule \\
IF answerGoForward(?p) \\
THEN Action = recommend Go-next Node \\
IF UPPER $=\varphi$ \\
THEN Action = recommend add-upper Node \\
IF answerGoMinimum(?p) \\
THEN Action = recommend Go-optional Node \\
\hline
\end{tabular}


With the objective of determining the different learning levels, the model incorporates indicators that allow intelligent system to compare among these levels. Agent rules provide recommendations for both student and teacher. These guide learning activities, selection of educational materials according with the possibilities, weaknesses and strengths of each student. In this way, this proposal models the personalization of learning process.

The use of e-portfolios implies carrying out processes of reflection, planning, synthesis, presentation, discussion and feedback, which are part of self-regulated learning. Thus, intelligent system uses all the evidences of progress that are found in the student e-portfolio and recommend when going forward or staying in the same level in the learning path.

The work presented in this paper presents a substantial difference with respect to traditional learning tools developed, since it not only identifies students who do not reach the minimum learning level desired, proposing suitable materials for their improvement, but also students who stand out and show interest, giving them the possibility to face new challenges.

As future work, the authors propose the definition of new indicators that complement the pedagogical perspective of each student in particular and the learning process in general, and also the integration of the ontologies into a software tool for managing the portfolio. In addition, it is proposed the integration of the software with the implementation of the intelligent agents modelled in order to have the recommender system available to assist the learning process in a personalized way and stimulating self-regulation.

Acknowledgments

Authors want to acknowledge to Universidad Nacional del Litoral Facultad de Ingeniería y Ciencias Hídricas, to Universidad Tecnológica Nacional Facultad Regional Santa Fe and to Consejo Interuniversitario Nacional (CIN, Argentina) for the support.

Funding

Universidad Nacional del Litoral CAI + D 50220150100017Ll; Universidad Tecnológica Nacional Facultad Regional Santa Fe PID 25/O4410.

Availability of data and materials

The Ontology network developed in the current study is available from the corresponding author on reasonable request.

Authors' contributions

LR, MG and LC have been the main contributor in the development of Ontology network. MG has developed the logical rules and software agent. CS has contributed in the state of the art analysis and in the implementation of ontology network. All authors read and approved the final manuscript.

Competing interests

The authors declare that they have no competing interests.

\section{Publisher's Note}

Springer Nature remains neutral with regard to jurisdictional claims in published maps and institutional affiliations.

\section{Author details}

${ }^{1}$ Facultad de Ingeniería y Ciencias Hídricas, GIDIS Research Group, Universidad Nacional del Litoral, Ciudad Universitaria, 80 Ruta Nacional 168, Santa Fe, Argentina. ${ }^{2}$ Facultad Regional Santa Fe, CIDISI Research Center, Universidad Tecnológica Nacional, Lavaisse 610, S3004EWB Santa Fe, Argentina.

Received: 8 January 2019 Accepted: 5 April 2019

Published online: 10 May 2019

References

Alexiou, A., \& Paraskeva, F. (2010). Enhancing self-regulated learning skills through the implementation of an e-portfolio tool. Procedia - Social and Behavioral Sciences, 2(2), 3048-3054. https://doi.org/10.1016/j.sbspro.2010.03.463. 
Allocca, C., d'Aquin, M., \& Motta, E. (2009). DOOR: towards a formalization of ontology relations. In International Conference on Knowledge Engineering and Ontology Development (KEOD). Madera.

Barberà, E., Bautista, G., Espasa, A., \& Guasch, T. (2006). Portfolio electrónico: desarrollo de competencias profesionales en la red. Revista de Universidad y Sociedad del Conocimiento (RUSC), 3(2), 55-66.

Barrett, H. C., \& Garrett, N. (2009). Online personal learning environments: structuring electronic portfolios for lifelong and lifewide learning. On the Horizon, 17(2), 142-152. https://doi.org/10.1108/10748120910965511.

Bloom, B. S., Engelhart, M. D., Furst, E. J., Hill, W. H., \& Krathwohl, D. R. (1956). Taxonomy of educational objectives: The classification of educational goals. Handbook I: Cognitive domain. New York: Longman.

Bolivar, C. R. (2011). Pruebas de rendimiento académico. Technical Report, Programa Interinstitucional Doctorado en Educación.

Chang, C. C., Tseng, K. H., \& Lou, S. J. (2012). A comparative analysis of the consistency and difference among teacher-assessment, student self-assessment and peer-assessment in a Web-based portfolio assessment environment for high school students. Computers \& Education, 58(1), 303-320. https://doi.org/10.1016/j. compedu.2011.08.005.

Chittum, J. R. (2018). The theory-to-practice ePortfolio: an assignment to facilitate motivation and higher order thinking International Journal of ePortfolio, 8(1), 27-42.

Collins, E., \& O'Brien, R. (2018). Highly structured ePortfolio platform for bachelor of nursing students: lessons learned in implementation. International Journal of ePortfolio, 8(1), 43-55.

Encalada, J., Santiesteban, K., Portela, Y., Cruz, S., \& Arboleda, M. (2017). The development of e-Portfolio for lesson study. In 2017 International Conference on Information Systems and Computer Science (INCISCOS), (pp. 274-278). Quito: IEEE. https:// doi.org/10.1109/INCISCOS.2017.35.

EPAC: ePortfolio-related Tools and Technologies. (2018). Retrieved Nov. 5, 2018, from http://epac.pbworks.com/w/page/ 12559686/Evolving\%20List\%C2\%A0of\%C2\%A0ePortfolio-related\%C2\%A0Tools

Escudero Escorza, T. (2000). La evaluación y mejora de la enseñanza en la universidad: otra perspectiva. Revista de Investigación Educativa, 18(2), 405-416.

García Carreño, I. D. (2012). Hacia una evaluación integral con e-portafolio por evidencia y bPortafolio. RELADA - Revista Electrónica de ADA - Madrid, 6(4), 274-281.

Grüninger, M., \& Fox, M. S. (1995). Methodology for the design and evaluation of ontologies. In Workshop on Basic Ontological Issues in Knowledge Sharing. Montreal.

Janssen, J., Berlanga, A., Vogten, H., \& Koper, R. (2008). Towards a learning path specification. International Journal of Continuing Engineering Education and Life Long Learning, 18(1), 77-97. https://doi.org/10.1504/ IJCEELL.2008.016077.

Jaramillo Roldán, R. (2004). La calidad de la educación: hacia un concepto de referencia. Revista Educación y Pedagogía 16(38), 91-100.

Leyva Leyva, L. M., Proenza Garrido, Y., Leyva Leyva, J. L., Varona, R. C., \& Romero Rodríguez, R. (2008). Reflexiones sobre la evaluación de la calidad del aprendizaje en la práctica pedagógica en la escuela primaria. Revista Iberoamericana de Educación, 44(7), 1-11.

Lorenzo, G., \& Ittelson, J. (2005). An overview of E-portfolios. EDUCAUSE Learning Initiative, 1, 1-27.

Marques, B., Villate, J., \& Carvalho, C. (2017). Analytics of student behaviour in a learning management system as a predictor of learning success. In 2017 12th Iberian Conference on Information Systems and Technologies (CISTI). Lisbon: IEEE. https:// doi.org/10.23919/CISTI.2017.7975863.

Mason, R., Pegler, C., \& Weller, M. (2004). E-portfolios: an assessment tool for online courses. British Journal of Educational Technology, 35(6), 717-727. https://doi.org/10.1111/j.1467-8535.2004.00429.x.

Meira Ferrão Luis, R. M., Llamas-Nistal, M., \& Fernández Iglesias, M. J. (2017). Enhancing learners' experience in elearning based scenarios using Intelligent tutoring systems and learning analytics: First results from a perception survey. In 2017 12th Iberian Conference on Information Systems and Technologies (CISTI). Lisbon: IEEE. https://doi.org/ 10.23919/CISTI.2017.7975976.

Morais, C., Alves, P., \& Miranda, L. (2017). Learning analytics na obtenção de indicadores de desempenho no ensino superior. In 2017 12th Iberian Conference on Information Systems and Technologies (CISTI). Lisbon: IEEE. https://doi.org/10.23919/ CISTI.2017.7975812.

Nalda, F. N. (2002). La evaluación del aprendizaje y su influencia en el comportamiento estratégico del estudiante universitario. Contextos educativos: Revista de educación, 5, 141-156.

NeOn Project. (n.d.). Retrieved Nov. 9, 2018, from http://www.neon-project.org.

Nguyen, L. T., \& Ikeda, M. (2014). ePortfolio system design based on ontological model of self-regulated learning. In 2014 IIAI 3rd International Conference on Advanced Applied Informatics, (pp. 301-306). Kitakyushu: IEEE. https://doi. org/10.1109/IIAI-AAI.2014.69

Peres, P., Oliveira, L., Jesus, A., \& Silva, A. (2017). Designing learning paths: Contributions to the organization of b-learning initiatives. In 2017 12th Iberian Conference on Information Systems and Technologies (CISTI). Lisbon: IEEE. https://doi.org/10. 23919/CISTI.2017.7975727.

Rezgui, K., Mhiri, H., \& Ghédira, K. (2018). Towards a common and semantic representation of e-portfolios. Data Technologies and Applications, 52(4), 520-538. https://doi.org/10.1108/DTA-01-2018-0008.

Rico Martín, A. M. (2010). El portafolios en las prácticas de enseñanza del grado en maestro en Educación. Revista Electrónica Interuniversitaria de Formación del Profesorado (REIFOP), 13(3), 37-45.

Romero, L., Gutiérrez, M., \& Caliusco, L. (2017). Semantic modeling of portfolio assessment in e-learning environment. Advances in Science, Technology and Engineering Systems Journal, 2(1), 149-156. https://doi.org/10.25046/aj020117.

Romero, L., Gutiérrez, M., \& Caliusco, M. L. (2016). Portfolio assessment to evaluate outcomes of learning in the e-learning environment. In 2016 11th Iberian conference on information systems and technologies (CISTI). Gran Canaria: IEEE. https:// doi.org/10.1109/CISTI.2016.7521406.

Romero, L., Gutiérrez, M., \& Caliusco, M. L. (2018). Conceptual modeling of learning paths based on portfolios: Strategies for selecting educational resources. In 2018 13th Iberian Conference on Information Systems and Technologies (CISTI). Caceres: IEEE. https://doi.org/10.23919/CISTI.2018.8399270. 
Stojanovic, L., Staab, S., \& Studer, R. (2001). eLearning based on the semantic web. In WebNet2001 - World Conference on the WWW and Internet, (pp. 23-27).

Studer, R., Benjamins, V. R., \& Fensel, D. (1998). Knowledge engineering: Principles and methods. Data \& Knowledge Engineering, 25(1-2), 161-197. https://doi.org/10.1016/S0169-023X(97)00056-6.

Suárez-Figueroa, M. C. (2010). NeOn Methodology for Building Ontology Networks: Specification, Scheduling and Reuse, Thesis Doctoral, Facultad de Informática - Universidad Politécnica de Madrid.

Taibi, D., Gentile, M., Fulantelli, G., \& Allegra, M. (2010). An ontology to model e-portfolio and social relationship in web 2.0 informal learning environments. International Journal of Computers Communications \& Control, 5(4), 578-585. https://doi. org/10.15837/ijccc.2010.4.2516.

Wang, S., \& Wang, H. (2012). Organizational schemata of e-portfolios for fostering higher-order thinking. Information Systems Frontiers, 14(2), 395-407. https://doi.org/10.1007/s10796-010-9262-0.

Weber, K., \& Myrick, K. (2018). Reflecting on reflecting: summer undergraduate research students' experiences in developing electronic portfolios, a meta-high impact practice. International Journal of ePortfolio, 8(1), 13-25.

Welty, C., \& Guarino, N. (2001). Supporting ontological analysis of taxonomic relationships. Data \& Knowledge Engineering, 39(1), 51-74. https://doi.org/10.1016/S0169-023X(01)00030-1.

Zimmerman, B. J. (2002). Becoming a self-regulated learner: an overview. Theory Into Practice, 41(2), 64-70. https://doi.org/10 1207/s15430421tip4102_2

Submit your manuscript to a SpringerOpen ${ }^{0}$ journal and benefit from:

- Convenient online submission

- Rigorous peer review

- Open access: articles freely available online

- High visibility within the field

Retaining the copyright to your article

Submit your next manuscript at $>$ springeropen.com 